\title{
ПЕРСПЕКТИВЫ РАЗВИТИЯ РЕГИОНАЛЬНОГО АВИАСТРОЕНИЯ В ПОСТПАНДЕМИЙНЫЙ ПЕРИОД
}

\author{
(C) 2021 Афян Арам Ишханович \\ кандидат экономических наук \\ МГИМО Университет, Россия, Москва \\ E-mail:aram8@yandex.ru
}

Экономические последствия пандемии коронавируса для мировой экономики всё еще не поддаются точной оценке. Однако масштаб ее влияния позволяет уже на экспертном уровне определить изменения, связанные с ней, как структурные трансформации характера деятельности всех экономических субъектов на мировом уровне. В данной статье рассмотрены проблемы и тенденции развития мировой авиационной отрасли в сегменте регионального авиастроения. В работе показано, что, хотя восстановление международных перевозок и происходит в рамках прогнозной динамики, сама структура мировых перевозок, а за ней и структура рынка продукции гражданского авиастроения могут претерпеть значительные изменения в скором будущем. Особое внимание уделено процессам восстановления коммерческой актуальности переориентации авиакомпаний с реактивных на турбовинтовые самолеты. Борьба авиакомпаний за увеличение доли на рынке в 2020 году переросла в борьбу за выживание, как хозяйствующего субъекта, вновь обратив и без того пристальное внимание на экономическую эффективность маршрутной сети и парка самолетов.

Ключевые слова: гражданское авиастроение, конкурентоспособность, мировой рынок, стратегическое управление, новые технологии, продуктовая линейка.

Особенности и тенденции развития пассажирооборота в мировой отрасли воздушного транспорта

Расширение мировой транспортной системы и пассажирооборота в частности с начала $\mathrm{XX}$ века было обусловлено во многом за счет появления и развития авиасообщений. Эти первые 100 лет истории гражданского авиастроения можно очень условно разделить на три этапа. На заре появления пассажирских самолетов, который можно обозначить первым этапом развития (с 1910-х по 1930-е годы), производители техники стремились создать самолеты, способные безопасно доставить хоть сколько-нибудь пассажиров по воздуху на дальние расстояния. Безусловно, мировая инженерная мысль с самого начала становления отрасли была направлена на достижение оптимального баланса надежности, вместимости, скорости и экономичности. Однако по-настоящему эффективные решения и бурный рост отрасль получила с середины 1930-х годов с началом выпуска массовых пассажирских самолетов. На этот период в том числе приходится открытие «реактивной эры» в мировой гражданской авиации, когда в 1958 году впервые количество пассажиров, перевезенных через Атлантический океан на самолетах превы- сило количество людей, перевезенных морским путём. Началом третьего этапа развития отрасли гражданского авиастроения можно обозначить появление широкофюзеляжного самолета и его первый полёт в 1969 году. Именно в этот период появились такие огромные двухпалубные авиалайнеры, как Boeing 747 и Airbus 380, способные перевозить более 850 пассажиров на расстояния до 16000 километров [1]. При этом научно-технический прогресс позволил добиться подобных результатов с максимальной эффективностью в соотношении всех показателей по параметрам экономики, безопасности и комфорта.

Современный облик мировой маршрутной сети авиасообщений сформировался к началу XXI века. К этому времени определились основные мировые и региональные центры экономической активности. При этом, если оценивать по характеру развития модельного ряда пассажирских самолетов, то потребность в региональных и ближнемагистральных авиаперелетах показала наибольший рост за этот период. Даже еще до мировой пандемии среднее количество пассажиров в самолетах, обслуживавших почти $70 \%$ всех маршрутов, составляло не более 150 человек [2]. 


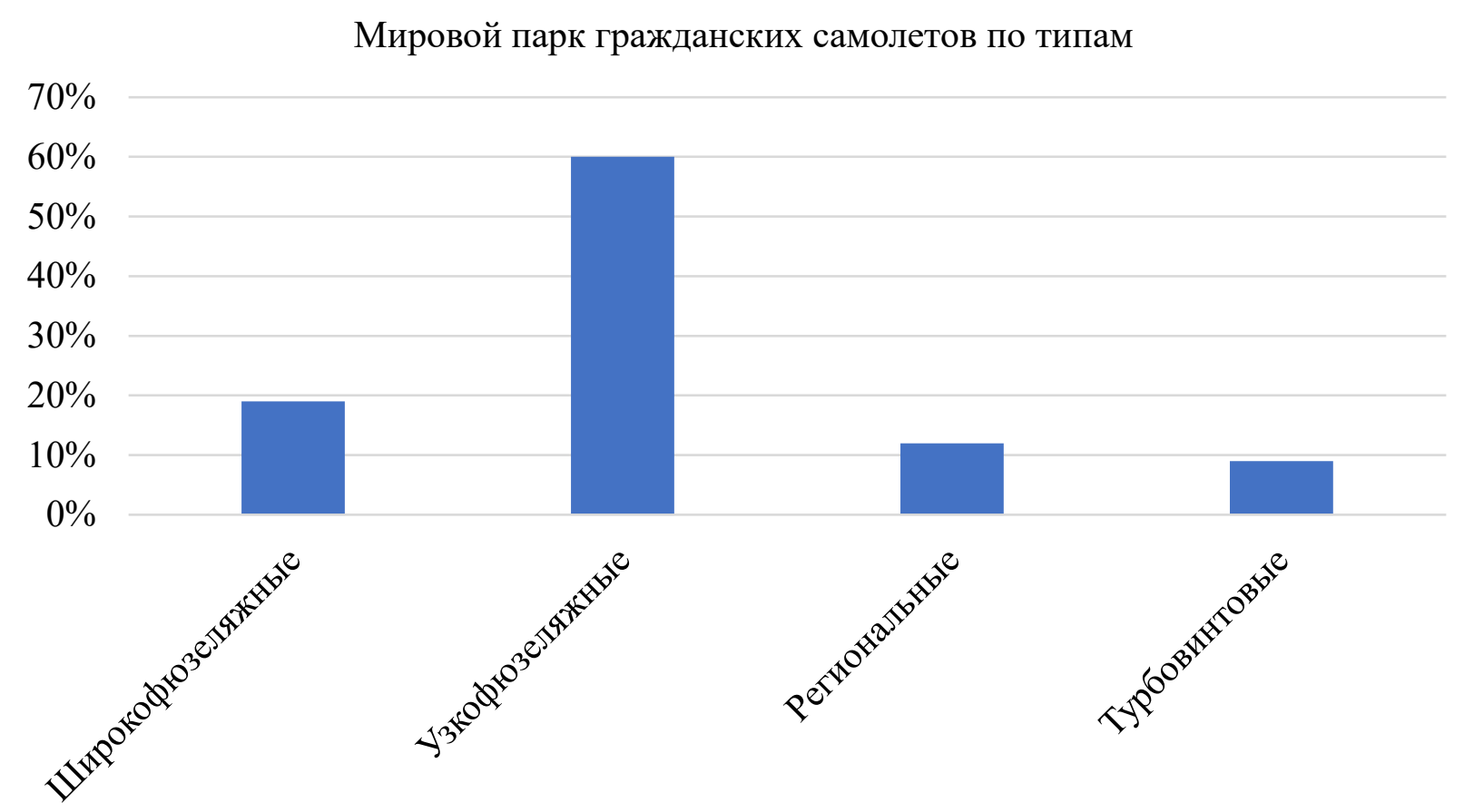

Puc. 1 Мировой парк гражданских самолетов по типам к началу 2021 г. Источник: Информационно-аналитический портал Statista. URL: https://www.statista.com

Исходя из сложившегося опыта деятельности авиакомпаний, если на маршрутной линии эксплуатируется и региональный реактивный самолет (RJ), и узкофюзеляжные самолеты (УФ) большей вместимости, то RJ, как правило, предназначен для начального этапа функционирования этой линии. Как только пассажиропоток на линии превысит 100 тысяч человек в год, то RJ заменяется УФ большей вместимости. При этом, с учетом совместной эксплуатации на линии RJ и УФ, инфраструктура аэропортов позволяет принимать УФ самолеты. Если на линии эксплуатируются совместно RJ и турбовинтовые самолеты, то турбовинтовые самолеты используются на период популяризации линии для RJ. Инфраструктура аэропортов позволяет эксплуатировать RJ самолеты. Группа линий, на которых эксплуатируются только RJ самолеты крайне малочисленна, и ее доля снижается.

Отметим, что развитие потребностей в авиаперелетах стало в некотором смысле коммерческой ловушкой для производителей региональных самолетов и привело к большим убыткам. Так, оценив динамику роста рынка авиаперевозок, некоторые авиастроительные компании (из России, Японии) вложили огромные инвестиции для разработки новых региональных самолетов с целью входа на быстрорастущий рынок. Однако, как видно из анализа выше, за период разработки и производства новых самолетов прояснилась реальная картина мировой потребности в этих типах воздушных судов, которая оказалась существенно ниже прогнозных расчетов. Таким образом, российские производители регионального самолета SSJ100 столкнулись с проблемой отсутствия заказчиков, а японский разработчик Mitsubishi и вовсе объявил в 2020 г. о временной приостановке программы регионального самолета MRJ после 10 лет разработки.

Однако представляется, что мировая пандемия коронавируса внесёт свои корректировки в устоявшиеся, как казалось, принципы развития рынка авиаперевозок. В результате массовых ограничений на международные перелеты наметился устойчивый тренд на развитие коротких региональных перевозок. Закрытие границ способствовало концентрации туристических потоков внутри стран, что проявилось уже в 2020 году и, вероятно, будет продолжено в краткосрочной перспективе по всеми миру. Кроме того, ограничение транснациональных пассажирских перелётов может сыграть стимулирующую роль и в переориентации бизнес-процессов на внутренний рынок и отечественный спрос в среднесрочной перспективе.

В условиях, когда из-за низкой доходной ставки окупаемость рейса достигается только при высоком коэффициенте занятости кресел, 
выбор воздушного судна правильной пассажировместимости становится актуальным как никогда ранее. Авиакомпании, обладающие компетенциями гибко планировать обслуживание своей маршрутной сети, оказываются в более выгодной позиции для восстановления и будущего роста. В этой связи может отмечаться обратная тенденция формирования парка авиакомпаний, когда в условиях недозагруженности ближнемагистральных рейсов, а также развития внутренних пассажиропотоков актуальным вновь становится возврат к активной эксплуатации региональных самолетов. В таком случае в наиболее выигрышном положении окажутся авиастроительные компании, имеющие развитые компетенции в поставке этого типа самолетов. В первую очередь это касается компании бразильской авиастроительной корпорации Embraer, которая, несмотря на непростое экономическое положение, спад в результатах коммерческой деятельности в период 2005-2020 годы, а также отмену объединения с Boeing, смогла сохранить и развить свои компетенции в отрасли и зафиксировать рост продаж.

Так, уже в четвертом квартале 2020 г. Embraer зафиксировала значительный рост числа поставок как на коммерческие, так и на деловые самолеты. За отчетный период компания передала заказчикам 43 самолета корпоративного класса. То есть за один последний квартал 2020 года было поставлено столько же самолетов, сколько за предыдущие три. Менеджмент компании отмечает, что в условиях пандемии деловая авиация оказалась более живучей, чем коммерческая. В настоящее время интенсивность эксплуатации самолетов корпоративного класса превышает 90\% от предкризисного уровня [3]. В секторе коммерческой авиации Embraer закрыл 28 поставок в четвертом квартале 2020 года и всего 16 за предыдущие девять месяцев [4].

Возобновление популярности региональных самолетов сформировало также новую тенденцию в этом сегменте рынка. Появился активный интерес авиакомпаний к турбовинтовым региональным самолетам, известным своей экономичностью в эксплуатации. Несмотря на неоспоримые преимущества реактивной авиации в скорости и тишине в салоне, в условиях кризиса и постоянно растущих цен та топливо экономичность турбовинтовых самолетов при относительно малых скоростях снова оказалась очень привлекательной. Если сравнить, напри- мер, турбовинтовой Bombardier серии DHC-8 с таким же по вместительности турбореактивным самолетом (50-70) мест, то первый по эксплуатации и обслуживанию окажется коммерчески эффективнее в среднем на 30-40\% [5]. Очевидно, что это неоспоримый аргумент, учитывая, что при большом пассажирообороте компании конкурируют за каждый процент эффективности. Еще большую актуальность этот вопрос имеет в секторе грузовых перевозок, где шумность не имеет определяющего значения из-за отсутствия пассажиров. При этом заказчикам авиационных грузов совершенно не критична скорость перевозки самолета, так как в логистических цепочках сам авиаперелет занимает незначительную долю от общего времени доставки. Это обстоятельство формирует в сегменте регионального авиасообщения очевидный тренд на переход на современные турбовинтовые самолеты. Именно поэтому при региональных перевозках на расстояния до 1000 км турбореактивные самолеты в краткосрочной и среднесрочной перспективе могут потерять привлекательность для авиакомпаний.

Одним из наиболее значимых трендов на постпандемийном рынке продукции гражданского авиастроения также следует обозначить рост влияния лизинговых компаний. Кризис 2020 года не только обрушил объемы перевозок и нанес воздушному транспорту колоссальные убытки, но также обусловил ряд структурных изменений, из-за которых отрасль никогда не станет прежней. К таким изменениям относится и рост парка лизинговых компаний, хотя эта тенденция наблюдалась уже несколько лет. 2020 г. внес дополнительный вклад за счет роста сделок возвратного лизинга (SLB), когда перевозчики, остро нуждающиеся в наличных средствах, продавали свои самолеты лизинговым компаниям с получением их обратно в лизинг или же просто уступали права собственности в обмен на долги. По данным аналитической компании Cirium, в 2021 году впервые за историю мировой гражданской авиации доля пассажирских воздушных судов, находящихся в лизинге, достигла 50\%. Более 200 лизинговых компаний владеют более чем 13 тыс. реактивных и турбовинтовых ВС, которые эксплуатируются примерно в 700 авиакомпаниях мира. Кроме того, лизингодатели располагают твердыми контрактами еще на 2,5 тысяч самолетов. Всего в мире, по данным на март 2021 г., согласно Cirium, насчитывается 
26370 пассажирских воздушных судна, из которых на хранении находится 8442, или 32\% общего парка. Этот результат существенно лучше показателя 2020 года, когда в разгар пандемии коронавируса было остановлено 63\% мирового флота пассажирских самолетов [6].

Сам лизинговый рынок также меняет свою структуру. Хотя в распоряжении большинства лизинговых компаний находится небольшое количество самолетов, почти три десятка крупнейших компаний располагают не менее чем 100 единиц авиатехники. Среди них наблюдается значительное расслоение, но наибольшие изменения произошли в результате крупнейшей сделки по поглощению, в ходе которой ирландская лизинговая компания AerCap присоединила самолетный лизинговый бизнес американской компании GECAS. В результате получилась компания, портфель которой превышает 2000 самолетов и более 300 вертолетов. Под ее контролем оказались парки примерно 250 авиакомпаний мира (почти 36\% их численности).

Таким образом, можно заключить, что роль лизинговых компаний, ставших крупнейшими владельцами и заказчиками воздушных судов, становится все более значительной как для авиакомпаний, так и для самолетостроителей.

\section{Основные производители региональных} самолетов

К середине 2000-х годов в мировой авиаиндустрии наметилась относительно определённая классификация типов гражданских самолетов, а также специализация стран по их производству. На рынке широкофюзеляжных и узкофюзеляжных самолетов установилась безусловная дуополия американского и европейского производителей. В то же время на рынке продукции регионального авиастроения, несмотря на прочные позиции лидеров отрасли, появились новые игроки, претендующие на определённые доли рынка.

Ниже рассмотрим основных производителей региональных самолетов на мировом рынке продукции гражданского авиастроения, а также их основные продукты, формирующие основу конкурентных стратегий в отрасли.

Embraer. К 2021 году безусловным лидером в области регионального авиастроения стала бразильская компания Embraer. В 2020 году компания поставила своим заказчикам 130 реактивных самолетов, в том числе 44 коммерческих лайнера и 86 бизнес-джетов. Это на 35\% меньше показателя 2019 года, когда было поставлено 198 самолетов. За 2020 г. чистый убыток Embraer co-

\section{Структура владения мирового парка лизинговыми компаниями}

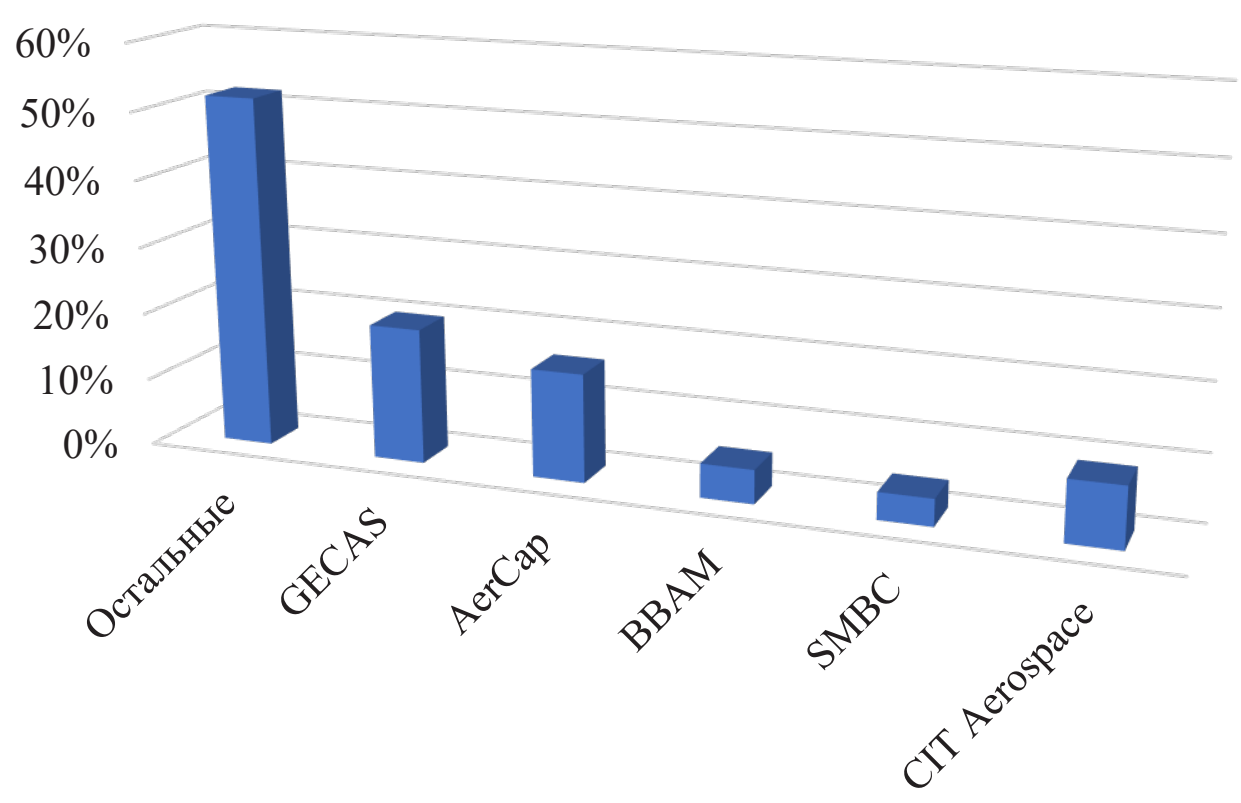

Puc. 2 Структура владения мирового парка лизинговыми компаниями.

Источник: Информационно-аналитический портал Statista. URL: https:/www.statista.com 
ставил 464 млн. долл., в 2019 г. - 218 млн. долл. Выручка за год снизилась на 30\%, до 1,8 млрд. долл.,- на 80\% из-за изменений в худшую сторону в секторе коммерческой авиации [7]. При этом, несмотря на сокрушительное снижение поставок, компания фактически продолжает оставаться лидером в выбранной нише. Обладая широким предложением по модификациям внутри семейства наряду с хорошими коммерческими возможностями, самолеты сери E-Jets занимают первое место по поставкам в своем сегменте рынка.

В связи с возросшей конкуренцией со стороны Airbus после заключения сделки по приобретению проекта Bombardier CSeries (в основном на североамериканском рынке), компаниями Embraer и Boeing было принято решение о создании совместного предприятия по разработке и продвижению на рынок всей линейки самолетов ERJ под контролем Boeing. В предполагаемом СП Boeing должен был получить 80\% акций подразделения коммерческих самолётов Embraer, бразильцам при этом оставались 20\%. Это решение было анонсировано 5 июля 2018 года. Однако в апреле 2020 года Boeing объявила о выходе из сделки по покупке подразделения по производству гражданских самолетов Embraer по причине критических финансово-экономических проблем.

Срыв сделки с Boeing не отразился на эффективности деятельности бразильского производителя, а спрос авиакомпаний на самолеты меньшей вместимости придали новый импульс развития модельного ряда Embraer. Аналитики компании прогнозируют, что рынки внутренних и региональных перевозок будут укрепляться по мере ослабления глобальной торговли, и правительства стран переориентируют национальные экономики на внутренние рынки и локализацию производства. В этой связи Embraer объявил о подготовке к запуску новой программы турбовинтового самолета размерности 70-100 кресел в 2022 году, с вводом эксплуатацию в 2027 году. Новая модель предлагается как замена парка ATR72 и de Havilland Dash 8-400.

Bombardier/Airbus. Канадская многопрофильная компания Bombardier начала заниматься авиастроением с середины 1980-х годов. До 2015 года компания всегда входила в тройку крупнейших производителей региональной авиатехники. Однако в жесткой конкурентной борьбе с младшими моделями линейки В737 на североамериканском континенте потерпела фиаско, когда США установили жесткие пошлины на перспективные самолеты CSeries, сделав самолеты неконкурентоспособными для авиакомпаний. В результате программа CSeries была продана Airbus в 2018 году, а самолеты линейки были переименованы в А220. Деятельность компании в 2019-2020 годах была сконцентрирована на продаже оставшихся авиационных проектов. В 2019 году производство турбовинтовых самолетов Q400 продано канадской компании De Havilland Aircraft of Canada за \$800 млн. [8] А в 2020 году программа региональных реактивных самолетов серии CRJ была продана японской Mitsubishi за \$550 млн. В отчёте 2020 года Bombardier сообщила о выпуске последнего пассажирского самолета CRJ900 и окончательно ушла с рынка коммерческих самолетов.

После поглощения канадского производителя Airbus предоставил модели CSeries доступ к системе своей глобальной дистрибуции и поддержки клиентов. Вся сборочная линия Bombardier CSeries в Мирабель, Квебек осталась действующей и выпускает самолёты для покупателей вне юрисдикции США. Самолеты CS100 и CS300 теперь представлены как A220-100 и A220-300 в линейке самолетов Airbus [9].

В мае 2020 года Airbus официально запустил новую сборочную линию семейства А220 в Мобиле, штат Алабама, возле первой площадки по сборке семейства A320. По сведениям Airbus к апрелю 2021 года в десяти авиакомпаниях мира эксплуатировалось 155 самолетов А220. При этом крупнейшим эксплуатантом является американский перевозчик Delta Air Lines с 49 самолетами А220 в парке.

ATR. Компания Aerei da Trasporto Regionale (ATR) является интегрированной франкоитальянской компанией, собственниками которой являются Airbus (50\%) и итальянский Leonardo (50\%). ATR является мировым лидером на рынке региональных турбовинтовых самолетов вместимостью до 90 посадочных мест (рис. 2.7), опережая канадский Bombardier, и в настоящее время производит два типа турбовинтовых самолетов: ATR 42 и ATR 72. Оба самолета обеспечивают эксплуатантам топливную эффективность, снижение выбросов и повышение экономичности, обеспечиваемой турбовинтовыми двигателями. Авиакомпании, обслуживающие небольшие рынки, отчаянно нуждаются в более экономичном топливе - поэтому самолеты ATR 
продолжают выполнять регулярные рейсы между региональными аэропортами и основными аэропортами и хабами, а компания ATR имеет более чем 200 заказов на ATR 72 новой версии. Результатом эффективной конкурентной стратегии ATR стали совокупные объемы продаж 1700 самолетов и организация работы около 200 операторов в более чем 100 странах. Более 1350 маршрутов в мире обслуживаются самолетами ATR. В целом, рыночная доля компании в заказах на самолеты от 50 до 90 мест составляет почти 40\%, в сегменте турбовинтовых двигателей этой категории 80\% [10].

Одной из главных конкурентных преимуществ компании является схожесть обоих самолетов по конструктивным признакам. Обе модели имеют одинаковое поперечное сечение фюзеляжа, используют аналогичные системы управления самолетом, оборудованы одинаковыми двигателями и пропеллерами, а также кабиной пилотов, что позволяет использовать одну систему подготовки летного состава на оба самолета, а также эффективно переквалифицировать пилотов одной модели в другую. Кроме того, оба самолета на 85\% состоят из одинаковых комплектующих и запасных частей. Эта общая экосистема позволяет существенно сократить расходы авиакомпании на подготовку летного экипажа, а также на техническое обслуживание и ремонт самолета.

COMAC, AVIC. Китайская государственная корпорация по производству авиакосмической техники СОМАС была учреждена в 2008 году с целью сокращения тотальной зависимости страны от крупнейших участников рынка авиатехники. Первый продукт представленный компанией к коммерческой эксплуатации в 2016 году - это региональный пассажирский самолет ARJ21, рассчитанный на перевозку от 70 до 115 пассажиров в зависимости от конфигурации [11]. Несмотря на большое количество иностранных комплектующих в конструкции самолета, работы по непосредственно конструированию самолета производились в Китае, что даёт основание производителю заявлять, что это первый пассажирский самолет подобного класса, разработанный в Китае.

Основными эксплуатантами ARJ21 являются китайские авиакомпании. Очевидно, темпы производства СОМАС не рассчитываются из количества реально заключенных контрактов, а основываются на ожидании заказа от мест- ных авиакомпаний. Интерес эксплуатантов к ARJ21, вероятно, стимулируется давлением со стороны правительства, а также может основываться на ожидании определенных выгод от государства взамен поддержки местного производителя. При этом китайское правительство применяет весь спектр финансовой поддержки для популяризации национального авиастроения на мировом рынке. В январе 2021 года стало известно, что китайская лизинговая компания China Aircraft Leasing Group закупит и передаст в эксплуатацию индонезийской авиакомпании TransNusa 30 самолетов ARJ21. Индонезийский перевозчик станет первой авиакомпанией за пределами KHP, заказавшей ARJ21, пусть и посредством финансового сопровождения китайской лизинговой компании. Тем не менее, по состоянию на 2021 год и по состоянию заказов программу ARJ21 рано называть успешным коммерческим продуктом.

Вторым проектом в региональном авиастроении Китайской народной республики является турбовинтовой самолет МА700, разработанный Сианьской компанией коммерческих самолетов при AVIC. Новый самолет является продолжением модельного ряда МА60 и МА600, которых в общей сложности поставлено 109 единиц китайским и зарубежным заказчикам. МА700 презентуется как значительно доработанный самолет, адаптированный к работе в условиях высокогорных аэродромов и жаркого климата. Салон рассчитан на перевозку 85 пассажиров, а более мощные канадские двигатели PW150A придают ему улучшенные эксплуатационные характеристики. В 2020 году компания AVIC сообщала о контрактах с 11 заказчиками, в том числе зарубежными, на поставку 285 новых турбовинтовых самолетов [12]. Однако, учитывая темпы роста пассажирооборота в КНР и протекционистскую политику правительства, иностранные покупатели на новую модель могут и не потребоваться. При этом серийное производство новой модели переносилось не раз, и к моменту выхода самолета его технические характеристики могут не только отличаться от заявленных показателей, но также и не дотягивать до уровня действующих моделей лидеров отрасли. По последним данным производителя начало коммерческой эксплуатации МА700 запланировано на 2022 год.

Mitsubishi SpaceJet, который до ребрендинга в 2019 году 16 лет носил название Mitsubishi Regional Jet,- это региональный турбореактив- 
ный самолет, проектируемый японской компанией Mitsubishi Aircraft Corporation. Программа разработки нового самолета финансировалась правительством Японии с 2003 года. По плану самолет должен иметь две модификации: MRJ70 на 76 мест и удлиненный MRJ 90 на 88 пассажиров. Несмотря на то, что к 2018 году программа летных испытаний была полностью выполнена, производитель неоднократно переносил сроки серийного производства в связи с необходимостью дополнительных доработок. В общей сложности на эту программу было израсходовано $\$ 10$ млрд. В конце 2020 года Mitsubishi Aircraft объявила об остановке разработки и сертификации самолета предварительно до 2023 года [13]. С учетом активных работ у конкурентов в отрасли это решение об остановке может иметь фатальные последствия для японского производителя. При этом необходимо отметить, что приобретение у канадского Bombardier проекта CRJ вовсе не означает переориентацию Mitsubishi на уже готовый самолет, так как по мнению экспертов отрасли японцы не планируют продолжать производство линейки CRJ, а собираются заниматься только техническим обслуживанием уже выпущенных канадцами самолетов.

Позиции российских производителей региональных гражданских самолетов

SSJ100. В 2000 году в России была начата программа разработки реактивного ближнемагистрального самолета SSJ100. В 2011 году самолет был введен в коммерческую эксплуатацию. Существенным отличием этого самолета от ранее создававшихся в СССР является высокий уровень международной кооперации.

По результатам 10 лет коммерческой эксплуатации SSJ100 выявился ряд проблем, совокупность которых не позволяет назвать этот самолет эффективным коммерческим проектом.

Во-первых, несмотря на то, что самолет успешно прошел сертификацию в том числе и в Европейском агентстве авиационной безопасности (EASA), уже на начальном этапе эксплуатации выявились системные технические недоработки, требующие устранения. Самой значительной недоработкой оказался дефект с двигателем самолета, на устранение которых производителю понадобился не один год [14].

Во-вторых, существенным препятствием к активной эксплуатации самолета стало отсутствие эффективной сети технического обслуживания. Еще одним обстоятельством, затруднившим популяризацию нового продукта на жестком сформировавшемся конкурентом рынке, стало отсутствие на начальном этапе продаж эффективной системы государственной поддержки и финансирования продаж самолета. Несмотря на всестороннюю политическую поддержку от правительства в продвижении SSJ100 среди традиционных заказчиков российской военной техники, стимулирование продаж гражданской авиационной техники требует несколько иного подхода. В эксплуатации пассажирских самолетов авиакомпании прежде всего ориентированы на коммерческие показатели продукта, в том числе и стоимость владения самолетом. В связи с этим представляется, что производитель SSJ100 мог бы достигнуть более весомых успехов в продажах самолетов, если бы изначально имел поддержку от правительства в вопросах государственного субсидирования продаж и эксплуатации SSJ100.

Таким образом, реальный рыночный платежеспособный спрос на SSJ100 имеет тенденцию снижения по причине публичности вопросов низкой надежности как самолета, так и двигателей. Анализ величины CASK (стоимость перевозки 1 кресло-километра) текущего облика SSJ100 показывает значительный проигрыш конкурентам, но благодаря ряду мероприятий, запланированных производителем, предполагается существенно улучшить эффективность эксплуатации SSJ100 по сравнению с существующей версией самолета. Достижение целевого показателя экономической конкурентоспособности SSJ100 может быть обеспечена при снижении CASK на 2 US cent (целевой CASK на уровне 6 US cent) путем выполнения следующих мероприятий:

Экономический анализ конкурентоспособности самолета SSJ100 [15]

\begin{tabular}{|l|c|c|c|c|}
\hline & SSJ100 & E190-E2 & CRJ-900 & A220-100 \\
\hline Годовой налет, л.ч. & 2400 & 2400 & 2400 & 2400 \\
\hline Вместимость, пасс. & 100 & 106 & 88 & 120 \\
\hline Расходы на ТОиР \$/л.ч. & 1500 & 910 & 770 & 950 \\
\hline Лизинговый платеж \$ / мес & 190000 & 250000 & 190000 & 250000 \\
\hline
\end{tabular}


- Увеличение налета путем повышения надежности самолета;

- Повышение топливной эффективности;

- Снижение стоимости технического обслуживания;

- Увеличение пассажировместимости до 108 кресел;

- Выдерживание лизинговой ставки.

Выполнение вышеуказанных мероприятий позволит достичь конкурентоспособного показателя стоимости технического обслуживания 900 \$ л летный час при налете 2400 л.ч. Эти показатели позволят обеспечить безубыточную эксплуатацию самолета SSJ 100.

ИЛ114. В 2014 году в России была начата программа модернизации и возобновления серийного производства турбовинтового регионального самолета Ил114-300. Работы были начаты с целью обеспечения внутреннего рынка авиаперевозок современными воздушными судами отечественного производства в классе пассажирских самолетов с количеством мест 52-64 пассажиров с полезной нагрузкой до 7 тонн. Новый самолет предназначен для замены на внутренних авиалиниях импортных самолетов аналогичного класса (ATR42, ATR72, Q400), а также старых типов самолетов Ан24/Ан26. Ил114-300 создается для местных авиалиний для эксплуатации в том числе в регионах со слабой аэродромной инфраструктурой, на малооборудованных площадках, коротких ВПП и на грунтовом покрытии [16]. Кроме того, новая модель приспособлена к эксплуатации в суровых северных условиях, полётам в Сибири и на Дальнем востоке. Именно этот самолет может стать ключом к развитию региональных перевозок. Одной из стратегических целей проекта по созданию этого самолета также является обеспечение независимости отечественной авиации от зарубежных производителей.

ОАК рассчитывает выйти на уровень производства в 12 самолетов в год. До 2030 года планируется поставить 100 самолётов, в том числе 50 - на внутренний рынок, 35 - государственным заказчикам, 15 - на экспорт.

Отметим, что на фоне возрастающего мирового интереса к турбовинтовым самолетам, как к более эффективному коммерческому решению на малых расстояниях, экспортный потенциал Ил-114-300 может быть существенно выше, чем 50 единиц. Региональные самолеты, как известно, востребованы в ряде регионов мира: в юго-восточной Азии, Латинской Америке, а Африке. Учитывая способность Ил-114-300 к взлету/посадке на сложных ВПП, конкурентоспособность самолета значительно повышается. Однако для достижения этой коммерческой цели также необходимо наличие эффективной сети послепродажного обслуживания во избежание неудачного опыта программы SSJ100. B этой связи проект Ил-114-300 при условии организации комплексной системы продвижения продукта имеет все шансы превратиться из решения задачи сугубо национального значения в эффективный коммерческий бизнес-проект международного масштаба.

\section{Библиографический список}

1. Официальный сайт компании Airbus [Электронный ресурс]: - Режим доступа: https://www.airbus.com/ aircraft/passenger-aircraft/a380/benefits-to-airlines.html (дата обращения 27.04.2021г.).

2. Официальный сайт Международной ассоциации воздушного транспорта (IATA) [Электронный ресурс]: Режим доступа: https://www.iata.org/en/pressroom/pr/2021-01-07-02/ (дата обращения: 20.04.2021 г.).

3. Информационный ресурс. Деловой авиационный портал. [Электронный ресурс]: - Режим доступа: http:// www.ato.ru/content/embraer-otmechaet-rost-postavok-kommercheskih-i-delovyh-samoletov (дата обращения: 10.04.2021 г.).

4. Официальный сайт компании Embraer. [Электронный ресурс]: - Режим доступа: https://www. embraercommercialaviation.com/category/share-feed/ (дата обращения: 10.04.2021 г.).

5. Дутов А.В., Клочков В.В., Рождественская С.М. Стратегическое управление технологическим развитием и научно-техническими знаниями (на примере авиастроения) // Друкеровский вестник. - 2019.- № 1.C.177-191.

6. Информационный ресурс. Аналитический портал Cirium. [Электронный ресурс]: - Режим доступа: https:// www.cirium.com/industry-solutions/air-finance/ (дата обращения: 25.04.2021 г.).

7. Официальный сайт компании Embraer. [Электронный ресурс]: - Режим доступа: https://www. embraercommercialaviation.com/wp-content/uploads/2021/03/Regional-Aircraft_-Resilience-and-Challengesof-an-Essential-Market-During-the-Pandemic.pdf (дата обращения: 27.04.2021 г.). 
8. 17 февраля 2021 года De Havilland объявила о приостановке производства модели Dash-8-400. При выкупе своего проекта у Bombardier в договоре была прописана аренда производственной площадки и аэродрома, срок которой истекает в 2021 году. Новое место производства к апрелю 2021 г. не выбрано.

9. Официальная сайт компании Airbus. [Электронный ресурс]: - Режим доступа: https://www.airbus.com/ aircraft/passenger-aircraft/a220-family.html (дата обращения: 29.04.2021 г.).

10. ОфициальнаясайткомпанииATR.[Электронныйресурс]:-Режимдоступа:https://1tr779ud5r1jjgc938wedppwwpengine.netdna-ssl.com/wp-content/uploads/2021/03/ATR-Annual-Results-EN.pdf （дата обращения: 25.04.2021 г.).

11. Официальный сайт компании СОМАС. [Электронный ресурс]: - Режим доступа: http://english.comac.cc/ products/rj/ (дата обращения: 24.04.2021 г.).

12. Официальный сайт компании AVIC. [Электронный ресурс]: - Режим доступа: https://www.avic.com/en/ civilaviation/commercialaircraft/678773.shtml (Дата обращения: 27.04.2021 г.).

13. Официальный сайт компании Mitsubishi aircraft corporation. [Электронный ресурс]: - Режим доступа: https://www.mhi.com/group/mitac/news/2020/20200615.html (дата обращения: 10.04.2021 г.).

14. SSJ100 мало летает из-за дефектов двигателя. [Электронный ресурс]: - Режим доступа: https://www. vedomosti.ru/business/articles/2018/11/21/787112-ssj100-malo-letaet (дата обращения: 12.04.2021 г.).

15. На основе анализа данных из отчетов по эксплуатации у авиаперевозчиков.

16. Официальный сайт ПАО «ОАК. [Электронный ресурс]: - Режим доступа: https://www.uacrussia.ru/ru/aircraft/ lineup/civil/il-114-300/ (дата обращения: 05.04.2021 г.). 